\title{
The disturbance leg-lift response (DLR): An undescribed behavior in bumble bees
}

\author{
Christopher A Varnon ${ }^{\text {Corresp., } 1}{ }^{1}$, Noelle Vallely ${ }^{1}$, Charlie Beheler $^{1}$, Claudia Coffin ${ }^{1}$ \\ ${ }^{1}$ Department of Psychology, Converse College, Spartanburg, South Carolina, United States \\ Corresponding Author: Christopher A Varnon \\ Email address: christopher.varnon@converse.edu
}

Background. Bumble bees, primarily Bombus impatiens and $B$. terrestris, are becoming increasingly popular organisms in behavioral ecology and comparative psychology research. Despite growing use in foraging and appetitive conditioning experiments, little attention has been given to innate antipredator responses and their ability to be altered by experience. In this paper, we discuss a primarily undescribed behavior, the disturbance leg-lift response (DLR). When exposed to a presumably threatening stimulus, bumble bees often react by lifting one or multiple legs. We investigated DLR across two experiments.

Methods. In our first experiment, we investigated the function of DLR as a prerequisite to later conditioning research. We recorded the occurrence and sequence of DLR, biting and stinging in response to an approaching object that was either presented inside a small, clear apparatus containing a bee, or presented directly outside of the subject's apparatus. In our second experiment, we investigated if DLR could be altered by learning and experience in a similar manner to many other well-known bee behaviors. We specifically investigated habituation learning by repeatedly presenting a mild visual stimulus to samples of captive and wild bees.

Results. The results of our first experiment show that DLR and other defensive behaviors occur as a looming object approaches, and that the response is greater when proximity to the object is lower. More importantly, we found that DLR usually occurs first, rarely precedes biting, and often precedes stinging. This suggests that DLR may function as a warning signal that a sting will occur. In our second experiment, we found that DLR can be altered as a function of habituation learning in both captive and wild bees, though the captive sample initially responded more. This suggests that DLR may be a suitable response for many other conditioning experiments. 


\section{The Disturbance Leg-Lift Response (DLR): An}

3 Undescribed Behavior in Bumble Bees

4

5

6 Christopher A. Varnon ${ }^{1}$, Noelle V. Vallely ${ }^{1}$, Charlie R. Beheler ${ }^{1}$, Claudia A. Coffin ${ }^{1}$

$7 \quad{ }^{1}$ Department of Psychology, Converse College, Spartanburg, SC, USA

9 Corresponding Author:

10 Christopher Varnon ${ }^{1}$

11580 E Main St, Spartanburg, Spartanburg, SC, USA

12 Email address: Christopher.Varnon@Converse.edu

13

14

15

16

17

18

19

20

Peer) reviewing PDF | (2020:07:50899:2:0:NEW 27 Jan 2021) 


\section{Abstract}

22 Background. Bumble bees, primarily Bombus impatiens and B. terrestris, are becoming 23 increasingly popular organisms in behavioral ecology and comparative psychology research.

24 Despite growing use in foraging and appetitive conditioning experiments, little attention has 25 been given to innate antipredator responses and their ability to be altered by experience. In this 26 paper, we discuss a primarily undescribed behavior, the disturbance leg-lift response (DLR). 27 When exposed to a presumably threatening stimulus, bumble bees often react by lifting one or 28 multiple legs. We investigated DLR across two experiments.

29 Methods. In our first experiment, we investigated the function of DLR as a prerequisite to later conditioning research. We recorded the occurrence and sequence of DLR, biting and stinging in response to an approaching object that was either presented inside a small, clear apparatus containing a bee, or presented directly outside of the subject's apparatus. In our second experiment, we investigated if DLR could be altered by learning and experience in a similar manner to many other well-known bee behaviors. We specifically investigated habituation learning by repeatedly presenting a mild visual stimulus to samples of captive and wild bees.

Results. The results of our first experiment show that DLR and other defensive behaviors occur

37 as a looming object approaches, and that the response is greater when proximity to the object is

38 lower. More importantly, we found that DLR usually occurs first, rarely precedes biting, and 39 often precedes stinging. This suggests that DLR may function as a warning signal that a sting 40 will occur. In our second experiment, we found that DLR can be altered as a function of 41 habituation learning in both captive and wild bees, though the captive sample initially responded 42 more. This suggests that DLR may be a suitable response for many other conditioning 43 experiments. 


\section{Introduction}

45

46

47

The study of the psychological abilities of bees has become an important research area. Such research provides insights to the valuable and global role of bees in agriculture and in the ecosystem. Additionally, bees are also excellent model organisms for investigating the relationships between complex behavior, ecological demands, and neurophysiology, and are the most researched invertebrate in recent comparative psychology (Varnon, Lang, \& Abramson, 2018). Psychological research with bees involves a number of topics including color perception (Koethe, Bossems, Dyer, \& Luna; 2016), olfactory learning (Riveros \& Gronenberg, 2009b), perception of time (Craig, Varnon, Sokolowski, Wells, \& Abramson, 2014), conditioned taste aversion (Varnon, Dinges, Black, Wells, \& Abramson, 2018), learned helplessness (Dinges, Varnon, Cota, Slykerman, \& Abramson, 2017), select and reject stimulus control (Scienza et al., 2019), concept learning (Giurfa, Zhang, Jenett, Menzel, \& Srinivasan, 2001), social transmission of learned behaviors (Alem et al., 2016), acquisition and flexibility of foraging skills (Raine \& Chittka, 2007; Strang \& Sherry, 2014), maximization of resources (Charlton \& Houston, 2010), effects of pesticides on learning (Stanley, Smith, \& Raine, 2015), alcoholism (Abramson, et al. 2006), and the neurophysiology of learning and memory (Hammer \& Menzel, 1995; Galizia \& Eisenhardt, 2011; Guirfa, 2003).

Honey bees (Apis mellifera) are currently the most popular species for psychological research, however, bumble bees, primarily Bombus impatiens in North America and B. terrestris in Europe, have become a popular alternative due to some practical challenges related to maintaining a honey bee laboratory, such as requiring a large outdoor foraging area. While recent psychological research with bumble bees shows promising potential, one area that is notably absent from the bumble bee literature is the study of innate defensive responses, especially in 
67 conjunction with learning. For example, in honey bees, sting extension response (SER)

68

69

conditioning research investigates how restrained bees learn to sting in response to a stimulus

associated with shock (Vergoz, Roussel, Sandoz, \& Giurfa, 2007; Tedjakumala \& Guirfa, 2013).

Similar work has also been conducted in other Hymenoptera (e.g., Desment et al., 2017).

Unfortunately, there is not yet analogous work with bumble bees. This is surprising given that

bumble bees appear to offer a unique and ideal behavior to fulfill this line of research, the disturbance leg-life response.

In this paper, we discuss the disturbance leg-lift response (DLR), and its potential use in psychological research. When exposed to a presumably threatening stimulus, bumble bees commonly react by lifting one or multiple legs (see Figure 1). While this behavior is primarily undescribed and we have only found brief mentions in two publications (Djegham, Verhaeghe, \& Rasmont, 1994; Free, 1958), it appears to occur in many Bombus species worldwide. (Curious readers may perform an online image search for the anthropomorphizations "bumble bee high five" or "bumble bee wave"). In our first experiment, we investigate the temporal relationships between DLR, biting and stinging as an invasive stimulus approaches in order to explore potential functions of the DLR. In our second experiment, we investigate if the DLR is a suitable behavior for conditioning procedures, similar to SER. Specifically, we compare habituation of the DLR across captive and wild samples. Finally, we discuss implications for future research with special considerations for the growing use of Bombus species as model organisms.

\section{Experiment 1 - The Role of DLR}

In this experiment, we explore the role of DLR as a reaction to potential danger to establish an understanding of the behavior as a prerequisite to later investigations of DLR conditioning. Many species emit specific responses, like DLR, when threatened. For example, 
90 spiders may lift several front legs to reveal fangs (Cloudsley-Thompson, 1995), while hissing

91 cockroaches produce an audible hiss (Hunsinger, Root-Gutteridge, Cusano, \& Parks, 2017;

92 Shotton, 2014). Although making distinctions between categories of antipredator responses can

93 be challenging, there are two major categories that could be considered for DLR: the aposematic

94 display, and the pursuit deterrence signal.

95 Conspicuous aposematic displays can signal toxicity or danger to a potential predator.

96 The vibrant colors of poison dart frogs in the family Dendrobatidae illustrate a case of honest

97 aposematic signals; the colors indicate that the frog possesses toxic alkaloid compounds (Maan

98 \& Cummings, 2012). Similarly, in the southern United States, the bright red banding of coral

99 snakes (Micrurus euryxanthus, M., fulvius, and M. tener) honestly signals a potent neurotoxic

100 venom. Several species of scarlet snake (Cemophora sp.) and kingsnake (Lampropeltis sp.) also

101 possess similar conspicuous red banding but lack venom. For the venomless mimic snakes, the

102 aposematic coloration is a dishonest signal (Greene \& McDiarmid, 1981).

103 Pursuit deterrence signals can alert a potential predator that it has been detected,

104 communicating vigilance and possibly fitness to the predator (Hasson, 1991). For example,

105 Thomson's gazelles (Eudorcas thomsonii) leap vertically into the air, a behavior known as

106 stotting (FitzGibbon \& Fanshawe, 1988), while white-tailed deer (Odocoileus virginianus) erect

107 their tails to reveal a high contrast white rump when a predator is detected (Bildstein, 1983), and

108 anole lizards (Anolis sp.) may signal fitness to potential predators with head bobs, pushups, or

109 dewlap extensions (Leal \& Rodríguez-Robles, 1995). While discussions of pursuit deterrence

110 signals typically suggest that they signal the ability to escape, it seems reasonable that they could

111 also signal readiness to use a defense such as venom. 
113 pursuit deterrence role. The stinging response of bumble bees and other Hymenoptera can clearly

114 serve as the foundation for an honest warning signal, and the vibrant color patterns of many bees

115 and wasps are one well-known aposematic display. Not only does the bright coloration lead to

116 predators quickly learning to not consume bumble bees (Brower, Brower, \& Westcott, 1960), but

117 this coloration also leads to mimics (Fisher \& Tuckerman, 1986; Plowright \& Owen, 1980). If

118 DLR functions in either an aposematic or a venom-based pursuit deterrence role, we would

119 expect it to be closely associated with, and precede, stinging. In the following experiment, we

120 investigate this possibility by examining the probability and order of DLR, biting and stinging in

121 response to invasive stimuli. If DLR often precedes, but does not follow, stinging, this would

122 provide the first evidence that DLR is an honest signal of envenomation potential.

\section{Methods}

124 Subjects

Captive worker bumble bees (Bombus impatiens, $\mathrm{n}=62$ ) collected from a single, captivebreed "Natupol” bumble bee colony purchased from Koppert Biological Systems Inc. (Howell, MI) were used as subjects. The bees were maintained in the ventilated plastic colony cage (24.5 x $21.5 \times 12 \mathrm{~cm}, 1 \times \mathrm{w} \times \mathrm{h}$ ) in which they were shipped. The outer cardboard layer, typically used to shield colonies from outdoor conditions, was removed except for the top piece, which ensured that the hive remained in darkness. The colony was placed on 40-watt intellitemp heating pad

131 (Big Apple Pet Supply; Boca Raton, FL), which maintained a temperature of about $31{ }^{\circ} \mathrm{C}$ inside

132 the hive. The colony was connected to an adjacent empty colony cage that served as a feeding area through a clear acrylic tube (2.5 cm inner diameter). Two lights (36" Zoo Med Reptisun T5- 
134 Ho Terrarium Hood, Zoo Med Laboratories Inc.; San Luis Obispo, CA) were placed

135 approximately $31 \mathrm{~cm}$ above the colony. These light fixtures provided a full range of illumination, 136 including ultraviolet (UV) light in the range of $280-400 \mathrm{~nm}$. Bumble bees can see UV light in 137 the range of $300-400 \mathrm{~nm}$ (Skorupski \& Chittka, 2010) and naturalistic lighting conditions may 138 be important for their growth and survival (Blacquière, Cornelissen, \& Donder, 2007). Lights and heat were automatically turned on at $7 \mathrm{AM}$ and turned off at $7 \mathrm{PM}$ each day to 140 help the bees maintain daily foraging patterns. The laboratory lacked any source of natural light, 141 and all other lights in the laboratory were also turned off by this time. Bees were allowed ad 142 libitum access to food (either a 50\% sucrose solution (w/w) or the "Bee-happy" solution 143 provided by Koppert Biological Systems Inc.) in the feeding cage via several paper towel wicks. 144 Water was provided directly in the hive via syringe. A three to one mixture of pollen (Stakich 145 Bee Pollen Powder, Stakich, Inc.; Troy, MI) and pollen substitute (Mann Lake Ultra Bee, Mann 146 Lake LTD.; Hackensack, MN) was made available ad libitum inside the hive. Captive worker bees were collected from the clear acrylic tube and the feeding cage, 148 chilled in a refrigerator around 1.1 $\mathrm{C}$ until inactive, then placed in the experimental apparatus. 149 After an experimental session was complete, the bees were chilled, weighed, measured, then marked with an acrylic paint marker between the wings on the thorax before being returned to

151 the colony. Captive bees collected and returned to the hive in this manner were observed alive 152 and healthy up to 8 weeks after participating in an experiment. As Converse College does not 153 require an institutional review for invertebrate research, no specific review was required for the 154 present study. 
155 Procedure

156 Subjects were placed in individual apparatuses after being collected. Each apparatus

157 consisted of a clear plastic cube $(2.6 \times 3 \times 2 \mathrm{~cm})$, made from a microscope cover slip container,

158 with two holes (2.55 mm diameter) drilled on opposite sides. The size of the apparatus allowed

159 the bees to freely move but did not permit flight or substantial relocation inside the apparatus.

160 After being placed in the apparatus, subjects were transferred to an experimental room, placed

161 approximately $1.2 \mathrm{~m}$ apart, and allowed to acclimate for three hours.

162 Each bee experienced five trials with a 15-minute intertrial interval (ITI) after the

163 acclimation period. Bees were randomly assigned to either an experimental or control group.

164 During trials for the experimental group, a researcher startled the bee by inserting a toothpick

165 approximately halfway $(1.3 \mathrm{~cm})$ into the apparatus for 10 seconds through the hole closest to the

166 bee. During this time, it was possible for the bee to physically contact the toothpick. An identical

167 procedure was used for the control bees, except that the toothpick was held outside of the

168 apparatus adjacent to the hole. This group controlled for the general approach of the

169 investigators, as well as the presence of a close object that could not be contacted by the bees.

170 During each trial, several behaviors were scored from video recordings. We recorded

171 both the occurrence of DLR and the number of legs lifted during each DLR. We specifically

172 defined DLR as when one or more legs were lifted above the bee, relative to the bee's position.

173 Legs that were lifted prior to the trial were not considered a DLR; observing the movement

174 during the trial was required to record a DLR. Biting was recorded as any time a bee visibly

175 opened and closed its mandibles during a trial. Often bees made mandible contact with the

176 stimulus, but this was not required. Finally, we recorded stinging any time the bee contacted the

177 stimulus with its abdomen or directed its abdomen toward the stimulus. These abdomen curls are

Peer] reviewing PDF | (2020:07:50899:2:0:NEW 27 Jan 2021) 
178 the first component of the sting extension response (Gage, Ahumada, Rivera, Graham, \&

179 DeGrandi-Hoffman, 2018). In most cases, the stinger was obvious and contacted the stimulus. In

180 some cases, the activity of the stinger was less clear, but the unusual abdomen curls and contact

181 were easy to observe. These abdomen curls were only observed when stimuli were presented

182 during the experiment or when the bees were handled during collection. We used a broad

183 definition of stinging, relative to DLR and biting, to capture instances where the sting extension

184 could not clearly be observed, or where the bee was not able to physically contact the stimulus

185 from its current location. For each trial, we also recorded the order in which DLR, biting, and

186 stinging occurred.

187 Analysis

All analyses were conducted through the StatsModels package (Perktold, Seabold \&

189 Taylor, 2018) included in the Anaconda distribution of Python, a free scientific analysis

190 distribution of the Python programming language (Anaconda, 2019; http://www.python.org).

191 Behavior sequences (e.g., DLR then bite, or bite then DLR then sting, etc.) were analyzed with a

192 series of repeated measures logistic regressions via generalized estimating equations (GEE;

193 Hardin \& Hilbe, 2003). We used this series of regressions in place of a multinomial logistic

194 regression as GEE controls for repeated measures within subjects. This technique is also less

195 sensitive to the need for many cases per variable than multinomial regression or chi square

196 analyses; an important consideration for our data, as statistical comparisons between commonly

197 and uncommonly observed behavior sequences answer important research questions. We used an

198 interceptless model where groups are treated as two mutually exclusive variables. By default, a

199 logistic regression's parameter estimates and associated $p$ values display a difference from a $50 \%$

200 binary chance level. As our sequence analysis considered 16 possible sequences, we subtracted

Peer] reviewing PDF | (2020:07:50899:2:0:NEW 27 Jan 2021) 
201 the $\log$ odds of 1/16 from all parameter estimates and confidence intervals, then calculated 202 corresponding $p$ values. Each behavior sequence is therefore tested for statistical difference from 203 chance (1/16) instead of a $1 / 2$ comparison that is arbitrary for this data. Individual parameter 204 estimates were compared directly by creating a $\mathrm{z}$ score by dividing the difference between the 205 estimates by the square root of the sum of the squared standard errors of the estimates (Clogg, 206 Petkova, \& Haritou, 1995; Paternoster, Brame, Mazerolle, \& Piquero, 1998). Even after 207 adjusting parameters by subtracting the $\log$ odds of $1 / 16$, the difference between estimates, $\mathrm{z}$ 208 score, and $p$ value are still the same as those normally reported by a regression that includes one 209 level of a categorical variable in the intercept.

210 Results

211 A visual overview of the findings can be seen in Figures 2 and 3, while subsequent 212 sections analyze our primary result, behavior sequence, in detail. Figure 2 shows the percent of 213 trials where a DLR, bite or sting occurred for bees in the experimental and control groups. Bees 214 in the experimental group displayed more behavior. For both groups, DLR was the most 215 common behavior. Bees in the experimental group were more likely to sting than bite, while bees 216 in the control group were more likely to bite than sting. The average number of legs lifted in 217 trials where DLR occurred can be seen in Figure 3. Not only were bees in the experimental group 218 more likely to emit a DLR (Figure 2), but they also lifted more legs on average. Both Figures 2 219 and 3 show little change across trial that would suggest habituation, sensitization, or fatigue.

220 While our analysis in subsequent paragraphs focuses on behavior sequences, we also included 221 our initial exploratory analysis of individual behaviors (without considering their order) in 222 supplementary material that will relate well to Figures 2 and 3. 
Table 1 shows the percent of trials where a particular behavior sequence occurred. For

224 each trial, the order of DLR, bite and sting were recorded, resulting in 16 possible sequences (no

225 tied rankings were observed). Corresponding statistical analysis that show the log odds of each

226 sequence compared to a 1/16 chance value can be seen in Tables 2 and 3, with Table 2

227 displaying information for the experimental group, and Table 3 displaying information for the

228 control group. We only included the groups as parameters in this analysis given the large number

229 of behavior sequences to be analyzed and the lack of a trial effect in previous graphs. The

230 direction and magnitude of the parameter estimates, as well as the $p$ values, reflect a difference

231 from the chance value. Although we used separate tables due to the large size of a single

232 combined table, the sequence analyses presented on Tables 2 and 3 should be interpreted

233 together.

234 Bees in the experimental group were highly active, only being inactive $3 \%$ of the time.

235 DLR was emitted first or by itself around $81 \%$ of trials, while biting and stinging rarely occurred

236 first or by themselves. All the DLR-first sequences, except for DLR:Bite, occurred significantly

237 more than chance ( $p$ values $<0.000$ ). The least common of the DLR-first sequences was the

238 DLR:Bite sequence, occurring during only $1 \%$ of trials, and was the only DLR-first sequence to

239 occur significantly less than chance $(p=0.017)$. Trials with a sting following DLR were much

240 more common (30\%), and trials with a bite and sting following DLR (in either order) were also

241 more common (31\%). Taken together, this indicates that in the experimental group, DLR is more

242 related to subsequent stings than to subsequent bites. Bees in the control group were inactive

243 during $51 \%$ of trials, significantly more than chance $(p<0.000)$. During trials when bees were

244 active, DLR often occurred by itself (31\%), or a bite occurred by itself (15\%). These were the 
245 only behaviors that occurred significantly more than chance ( $p$ values $<0.002$ ). Sequences of 246 multiple behaviors were rare.

Table 4 shows pairwise comparisons between DLR:Bite and other DLR-first sequences,

248 as well as comparisons between DLR:Sting and other DLR-first sequences for the experimental

249 group. The estimate differences and $\mathrm{z}$ scores were calculated from the parameter estimates and

250 standard errors reported in Tables 2 and 3. The pairwise comparisons show that the DLR:Bite

251 sequence occurs significantly less than all other DLR-first sequences ( $p$ values $<0.000$ ).

252 Conversely, the DLR:Sting sequence occurs significantly more than DLR:Bite, and other DLR-

253 first sequences ( $p$ values $<0.009$ ) except for DLR alone. Though DLR:Sting does occur more

254 than DLR alone, the difference is not significant $(p=0.064)$. Note that for this series for pairwise

255 comparisons, it may be appropriate to use a multiple comparison correction to adjust the

256 significance threshold. For example, the conservative Bonferroni correction would involve

257 dividing the alpha level by the number of comparisons, in this case 0.05 divided by 7 produces a

258 new significance threshold of 0.007 , which may affect interpretation of the comparisons between

259 DLR:Sting and DLR-first sequences containing both a sting and a bite. The reader is free to use

260 whichever correction technique they deem appropriate.

261 Taken together, the findings reported in Tables $1-4$ strongly suggest that DLR is more

262 related to subsequent stinging than it is to subsequent biting for the experimental group. This is

263 also in line with our supplementary analysis of individual behaviors. Ultimately, the fact that

264 DLR often precedes stinging in the experimental group, the group where stinging frequently

265 occurred, indicates DLR may function to signal potential predators that a sting is imminent. 


\section{Discussion}

268 precedes stinging, but rarely precedes biting alone. We also demonstrate that the probability of

269 DLR is sensitive to stimulus intensity, as the increased proximity to the stimulus in the

270 experimental group, compared to the control group, altered behavior. Together, these results

271 suggest that DLR is an honest signal that indicates stinging may occur. DLR may function in

272 either an aposematic or a pursuit deterrence role, and these functions may not be mutually

273 exclusive. Given the already bright coloration of bumble bees, it is possible that DLR serves as a

274 multimodal enhancement of existing aposematic signals, adding a conspicuous posture to vibrant

275 colors (for discussions on multimodal antipredator signals see Ritson-Williams \& Paul, 2007;

276 Rowe \& Guilford, 1999; and Rowe \& Haplin, 2013). If DLR has a pursuit deterrence function, it

277 may signal that the bee is aware of a potential predator and will sting if pursued.

278

While DLR likely signals a sting may occur, DLR can also occur alone. In the control

279 group, bees emit DLR but rarely sting. This likely occurs because the distant stimulus is intense

280 enough to elicit DLR, but does not support stinging. In the wild, if DLR is successful at

281 preventing a potential predator attack, it may occur without subsequent stinging behavior.

282 Therefore, the occurrence of DLR in the control group is consistent with an honest signal 283 interpretation.

284 While our experiment clearly indicates a temporal connection between DLR and stinging, 285 additional research is needed to clarify DLR's specific antipredator function. Such research will 286 need to consider what stimuli and predators elicit DLR, and equally importantly, how predators 287 respond. Field experiments may also study DLR in situ, providing bees with a number of 288 alternative behaviors, including fleeing. Such ecologically valid research may be required to 
289 completely determine the function of DLR. For example, if DLR functions strictly as a pursuit 290 deterrence signal, bees may emit a DLR, then flee if a predator approaches, while if DLR has 291 only an aposematic function it may not be related to any antipredator behavior other than 292 stinging.

In addition to further clarifying the function of DLR, our initial work facilitates many

294 295

296

297

298

299

300

301

302

303

304

305

306

307

308

309

310

additional research topics. For example, research may consider how DLR relates to specific stimulus modalities or intensities, and if predators have learned or innate responses to DLR. Research should also consider the extent that DLR occurs in other Bombus species, and if it differs across species. Studies of individual differences will likely also be fruitful, especially considering recent literature on the size-dependent behavior in bumble bee workers (e.g. Jandt, Huang, \& Dornhaus, 2009; Kodaira, Ohtsuki, Yokoyama, \& Kawata, 2009; Raine \& Chittka, 2008; Riveros \& Gronenberg, 2009a; 2009b; Spaethe \& Weidenmüller, 2002). Finally, as bees are social animals, future work should also consider social factors, such as if DLR can be elicited by other bees or if DLR affects adjacent bees. It may also be possible that DLR, like a number of other behaviors, is affected by alarm pheromones (e.g., Avalos et. al., 2017; Rossi, N., d'Ettorre, P., \& Giurfa, M., 2018). Given that bumble bees possess tarsal glands (Pouvreau, 1991; Schmitt, 1990), social odors may even be released during DLR.

\section{Experiment 2 - Habituation of DLR}

In this experiment, we investigated the possibility that DLR could change as a function of learning. Specifically, we wanted to know if DLR habituates to repeated mild stimuli. Habituation, defined as the diminishing of a response, emotional or physical, to a repeated stimulus (Thompson \& Spencer, 1966), is a simple form of learning that can be observed across

Peer] reviewing PDF | (2020:07:50899:2:0:NEW 27 Jan 2021) 
311 nearly all species, from planarians (Nicolas, Abramson, \& Levin, 2008) to rodents (Geyer \&

312 Braff, 1987). Habituation of disturbance responses has also been documented in many species.

313 For example, hissing cockroaches may cease emitting their disturbance hiss in the presence of

314 specific handlers (Davis \& Heslop, 2004), rattlesnakes show a reduction in latency and duration

315 of rattling in response to a startling stimulus (Place \& Abramson, 2008), and the gill withdrawal

316 reflex of the sea hare Aplysia is also known to habituate (Carew, Pinsker, \& Kandel, 1972).

317 Studies of habituation are also often the foundation for other procedures, including investigations

318 of mental health (Akdag, Nestor, O'Donnell, Niznikiewicz, Shenton, \& McCarley, 2003; Geyer

319 \& Braff, 1987; Jaycox, Foa, \& Morral, 1998), and neurological processes related to learning and

320 memory (Castellucci \& Kandel, 1974; Castellucci, Pinsker, Kupfermann, \& Kandel, 1970). If

321 DLR can be altered through habituation learning, this opens new possibilities in behavioral and 322 physiological research with bumble bees.

323 In addition to discovering if DLR can change as a function of learning, we were also 324 interested in differences across populations due to differences we observed in pilot research.

325 Specifically, we compared samples of captive bred to wild caught bumble bees. Given the 326 substantial number of findings on behavioral differences in honey bees due to breed, genetics 327 and environment (e.g., Alaux et al., 2009; Schulz, Haung, \& Robinson, 1998; Sheppard, Arias, 328 Grech, \& Meixner, 1997; Spivak, 1997; Tautz, Maier, Groh, Rössler, \& Brockman, 2003), it is 329 reasonable to investigate if some differences may be found between captive bred and wild caught 330 bumble bees. If DLR and habituation of DLR are observed across samples of both populations, 331 this would also suggest that DLR may be a robust behavior to study in learning experiments.

332 This would be a beneficial comparison considering the use of both wild and captive bees in the 333 literature. 


\section{Methods}

\section{Subjects}

Both captive $(n=64)$ and wild worker bumble bees $(n=64)$ were used in this experiment. Captive bees were acquired and maintained in a similar manner as described in experiment 1 with a few exceptions. The captive colony was connected to a screen flight cage

339 (91 x $46 \times 46 \mathrm{~cm}, 1 \times \mathrm{x} \times \mathrm{h}$ ), made from a modified Zoo Med "Reptibreeze" reptile cage via a 16

$340 \mathrm{~cm}$ long, clear acrylic tube $(2.5 \mathrm{~cm}$ inner diameter). In this flight cage, bees fed from plastic

341 dishes. Two lights (one 36" Zoo Med Reptisun T5-Ho Terrarium Hood and one 30-38" Zoo Med

342 Reptisun LED Terrarium Hood) were placed approximately $31 \mathrm{~cm}$ above the colony, providing a 343 full range of light.

344 Captive bees were collected in the flight cage and prepared in a similar manner as

345 described in the previous experiment and were observed alive and healthy up to 4.5 weeks after 346 participating in an experiment. Thirty-two captive bees were collected from one colony in 2018, 347 while the remaining 32 captive bees were collected from a second colony in 2020 . Wild worker 348 bees were collected while foraging, primarily on clover and Abelia, at the Converse College 349 campus (Spartanburg, SC). Thirty-two wild bees were collected during July 2018, while the 350 remaining 32 wild bees were collected during August and September 2020. Procedures for 351 capturing, chilling, using, and marking wild bees were similar to the procedures for captive bees.

352 Wild bees were released at the capture location, and many immediately returned to foraging.

353 Marked wild bees were observed foraging two weeks after the experiment. As Converse College

354 does not require an institutional review for research with non-threatened invertebrates, no

355 specific review or permits were required for the present study. 
357

358

359

360

361

362

363

364

365

366

367

368

369

370

371

372

373

374

375

376

377 trial to determine if DLR would occur to other stimuli and verify that any decrease in DLR 378 during the preceding 10 habituation trials was not caused by fatigue. The 12 th trial was a return

Subjects were placed in individual apparatuses after being collected. Each apparatus consisted of a capsule formed from a clear acrylic tube ( $4.5 \mathrm{~cm}$ long, $2.5 \mathrm{~cm}$ inner diameter), with two white plastic caps sealing the tube. Two holes $(0.4 \mathrm{~cm}$ diameter $)$ were drilled near the center of each cap. Each apparatus was placed approximately half a meter apart, and bees were allowed an acclimation period of 45 minutes.

Each bee experienced 10 trials with a seven-minute ITI after the acclimation period was complete. During each trial, a researcher startled the bee by presenting a hand $15 \mathrm{~cm}$ above the apparatus, rapidly lowering it to approximately $6 \mathrm{~cm}$ above the apparatus, rotating the hand once in a clockwise circular motion, and then withdrawing the hand. As strong stimuli can inhibit habituation or cause sensitization, we used this relatively mild stimulus, compared to those used in the first experiment, to increase the chance that habituation could be observed. The bees' response was recorded during the two-second stimulus presentation and for three seconds after the presentation. DLR was recorded as a binary response and no other behaviors were recorded. Subjects collected in 2020 also experienced three additional trials. On the 11 th trial, the bottom of the apparatus was tapped once, out of view of the subject. This trial served as a dishabituation

trial to determine if DLR would occur to other stimuli and verify that any decrease in DLR

Peer] reviewing PDF | (2020:07:50899:2:0:NEW 27 Jan 2021) 
379 to the standard habituation trial. Finally, on the $13^{\text {th }}$ trial, subjects were collected by reaching

380 directly toward the front of the apparatus, visible to the subject, and holding a hand adjacent to,

381 but not touching, the apparatus for the five-second observation period before placing the

382 apparatus in the refrigerator for chilling. All bees, in both 2018 and 2020, were chilled after

383 recollection, marked, and returned to their colony or the collection area.

\section{Analysis}

385

386

387

388

389

390

391

392

393

394

395

396

397

398

399

We analyzed the probability of DLR across trial using repeated measures logistic regression via GEE. As with previous logistic regressions, we use an interceptless form so that the parameters can be directly compared to a chance value (in this case $50 \%$ ), then compared them to each other by creating a $\mathrm{z}$ score by dividing the difference between the estimates by the square root of the sum of the squared standard errors of the estimates. As initial analysis revealed no significant differences between bees in the 2018 and 2020 collection periods ( $p$ values < 0.489), and there was no theoretical reason to expect differences, we did not include collection period as a parameter in our main analysis.

\section{Results}

Figure 4 shows the percent of captive and wild bees emitting DLR across the 10 habituation trials in both the 2018 and 2020 collection periods while Table 5 shows corresponding statistical analysis. The captive bees were initially much more likely to respond; nearly $65 \%$ of captive bees responded compared to around $35 \%$ of wild bees. The analysis shows that the initial probability of response for captive bees was significantly greater than chance $(p=$ 0.005). Wild bees initially responded less than chance, but not significantly so $(p=0.157)$. A

Peer] reviewing PDF | (2020:07:50899:2:0:NEW 27 Jan 2021) 
400 direct comparison of the parameters revealed that captive bees were significantly more likely to 401 initially respond than the wild bees (estimate difference $=0.931, \mathrm{z}=2.899, p=0.004$ ). The

402 probability of response decreased significantly across trials for both captive and wild bees at a 403 somewhat similar rate $(p$ values $<0.000)$. Though the captive bees showed a slightly stronger 404 effect, a direct comparison reveals that this difference was not significant (estimate difference $=$ $405-0.030, \mathrm{z}=-0.549, p=0.583)$.

The final three trials, also shown in Figure 4, were only conducted with subjects collected 407 in 2020. Corresponding analysis comparing the final three trials to trials 1 and 10 can be seen in 408 Table 6. While the original GEE regression is shown in supplemental material (Table S4), it is 409 more useful to interpret the pairwise comparisons shown in Table 6 that were derived from the 410 GEE regression. The $11^{\text {th }}$, dishabituation trial shows the probability of response returned to 411 nearly a trial 1 level, as does the $13^{\text {th }}$, collection trial. The analysis shows that for both captive 412 and wild bees, these response levels are statistically indistinct ( $p$ values $>0.317)$. The $12^{\text {th }}$ trial 413 was a return to a standard habituation trial and approximately follows the trends seen in the 414 previous 10 habituation trials. The analysis shows that, although the response level for wild bees 415 on the $12^{\text {th }}$ trial was somewhat higher than might be expected, for both captive and wild bees, 416 these response levels are statistically indistinct ( $p$ values $>0.453)$. Both trial 10 , the final 417 habituation trial, and trial 12 , the return to habituation trial, showed significantly lower 418 probabilities of response than trial 11 , the dishabituation trial, and trial 12 , the collection trial $(p$ 419 values $<0.032$ ). As with the previous pairwise comparisons in experiment 1 , it may be 420 appropriate to use a multiple comparison correction to adjust the significance threshold. In this 421 case, interpretations of comparisons between the wild bees' probability of response on trial 12 422 may change slightly. Overall, the tendency of bees to perform DLR when stimuli were presented 
423 in the $11^{\text {th }}$ and $13^{\text {th }}$ trials suggests that the decrease in DLR during the habituation trials occurred

424 due to habituation learning, not motor fatigue or sensory adaptation.

\section{Discussion}

427 documented differences in DLR across samples of captive and wild populations. While both

428 samples showed a similar rate of habituation, the captive bees were initially more likely to

429 perform DLR. This difference in DLR may have occurred for two different reasons. First, the

430 samples of worker bees we collected from captive and wild populations may have differed in

431 role specialization. Bumble bee castes include the reproductive queen and drone castes, as well

432 as the primarily non-reproductive worker caste frequently used in research. Workers may be

433 further specialized. The smaller worker bees are more likely to feed larvae and attend to hive

434 maintenance, while larger workers act as foragers. In bumble bees, role specialization appears to

435 be determined during early development, and research suggests that physical dimensions can

436 predict behavioral performance (Jandt, Huang, \& Dornhaus, 2009; Kodaira, Ohtsuki, Yokoyama,

437 \& Kawata, 2009; Raine \& Chittka, 2008; Riveros \& Gronenberg, 2009a; 2009b; Spaethe \&

438 Weidenmüller, 2002).

439 The bees sampled from our captive population were significantly smaller than those from

440 our sample of wild bees, suggesting the wild bees were more likely to be foragers. The wild bees

441 were also clearly collected during the act of foraging, further increasing our confidence they fit

442 this role specialization. While our captive bees were also collected in their foraging area, we are

443 less confident this collection method ensures they are true foragers due to one of the challenges

444 of maintaining an indoor bumble bee hive. In laboratory colonies, bumble bee workers may not 
445 return to the hive after feeding, and may instead inhabit a flight cage or feeding area. Workers

446 may build clusters of cells near a food dish, store food, and even raise drones. We call this

447 tendency the "lost bee effect." If not carefully managed, this may result in half the colony

448 moving away from the hive within a month (see Figure S1 in the supplemental material).

449 Although not widely published (we have only seen this reported in Jandt \& Dornhaus, 2009 and

450 Blacuiére, Cornelissen, \& Donders, 2007), the lost bee effect appears to be a common issue.

451 While there is no clear solution, preventative measures include capturing lost bees each day,

452 returning them to the colony, and cleaning the flight cage to remove odors (F. Muth, personal

453 communication, June, 2018); capturing and returning lost bees while also killing repeat offenders

454 (J. Jandt, personal communication, June, 2018); feeding the bees inside the hive and completely

455 preventing access to other areas (W. Gronenberg \& A. Riveros, personal communication, June,

456 2018); and providing a smaller antechamber between the hive and the flight cage to encourage

457 lost bees to build closer to the hive (J. Nieh, personal communication, June, 2018). While our

458 observations and the above communications are in regards to the North American Bombus

459 impatiens, the lost bee effect also occurs in the European B. terrestris (L. Chittka, personal

460 communication, August, 2018). Given the tendency of worker bees to become "lost", it may not

461 be possible to ensure that bees collected near food are the larger, foraging-specialized workers.

462 Instead, collected subjects may also consist of smaller bees specialized for brood care and hive

463 maintenance. While a growing body of research demonstrates the usefulness of laboratory

464 colonies, the lost bee effect indicates they may not be thriving, and this may impact their use as

465 model organisms. In our case, the lost bee effect may have made our sample of captive bees less

466 likely to be foragers. 
A second possible reason for the difference in DLR between captive and wild bees may

468 be the distinct experiences of bees raised indoors compared to those of wild bees. Captive bees

469 were only exposed to stimuli in their hive and flight cage, and ultimately experienced only a

470 small number of stimuli before research. Conversely, wild bees likely contact many stimuli

471 during daily foraging including other insects, birds, pedestrians, and even landscaping

472 equipment. It is possible that exposure to a wide variety of stimuli served to acclimate the wild

473 bees to mild visual stimuli, such as the hand wave used in this experiment.

474 Regardless of the difference in initial rate of DLR, both captive and wild bees showed

475 clear habituation trends, and thus our experiment suggestions expansive opportunities for a new

476 area of non-associative learning research with bumble bees. Future research may consider the

477 principles of habituation and sensitization outlined by Thompson and Spencer (1966), Groves

478 and Thompson (1970), and Rankin et al. (2009). For example, altering the time between stimulus

479 presentations may change the rate of habituation, and placing the animal in an agitated state prior

480 to habituation trials may instead result in sensitization. Future work may also consider exploring

481 classical conditioning or operant conditioning of DLR. This would be a reasonable next step

482 considering the reports of sting extension response (SER) conditioning in honey bees, though the

483 primary author and one reviewer note that SER conditioning may be less robust than the

484 literature suggests. Additionally, various DLR conditioning studies could be used as a basis for

485 research on pesticides, sensory perception, memory, pharmacology, and neurophysiology

486 research, as conditioning research with honey bees has also done for these same topics (e.g.,

487 Abramson, Squire, Sheridan, \& Mulder, 2004; Abramson et al., 2006; Faber, Joerges \& Menzel,

488 1999; Giurfa et al., 2009; Linader, de Ibrra, Laska, \& 2012; Mustard, Dews, Brugato, Dey, 
489 Wright, 2012; Varnon, Dinges, Black, Wells, \& Abramson, 2018; Vergoz, Roussel, Sandoz \& 490 Giurfa, 2007).

\section{Conclusions}

492

493

494

495

496

497

498

499

500

501

502

503

Our experiments document a primarily undescribed behavior, the disturbance leg-lift response (DLR). We suggest an antipredation role for DLR, show that DLR can change as a function of learning, and outline future considerations for DLR as a behavior of interest for both behavioral ecology and comparative psychology. A growing body of research with bumble bees is indicating they are becoming an important model organism for ecological, behavioral, and physiological research. We hope that our work will stimulate additional research on DLR, and on bumble bees in general. We also hope that special considerations will be given to reporting not only what bumble bees can do, but also what they cannot do. Reporting differences, including deficits, is an important component of research in animal behavior (Avarguès-Weber \& Giurfa, 2013), and this is especially important for new model organisms. 


\section{References}

505

506

507

508

509

510

511

512

513

514

515

516

517

518

519

520

521

522

523

524

525

Abramson, C. I., Squire, J., Sheridan, A., \& Mulder Jr., P. G. (2004). The effect of insecticides considered harmless to honey bees (Apis mellifera): Proboscis conditioning studies by using the insect growth regulators tebufenozide and diflubenzuron. Environmental Entomology, 33(2), 378-388. doi: 10.1603/0046-225X-33.2.378

Abramson, C. I., Stone, S. M., Ortez, R. A., Luccardi, A., Vann, K. L., Hanig, K. D., \& Rice, J. (2006). The development of an ethanol model using social insects 1: Behavior studies of the honey bee (Apis mellifera L.). Alcoholism Clinical \& Experimental Research, 24(8), 1153-1166. doi: 10.1111/j.1530-0277.2000.tb02078.x

Akdag, J. S., Nestor, P. G., O'Donnell, B. F., Niznikiewicz, M. A., Shenton, M. E., \& McCarley, R. W. (2003). The startle reflex in schizophrenia: Habituation and personality correlates. Schizophrenia Research, 64, 2-3(15), 165-173. doi: 10.1016/S0920-9964(03)00059-8

Alaux, C., Saurabh, S., Hasadsri, L., Hunt, G. J., Guzmán-Novoa, E., DeGrandi-Hoffman, G., ... Robinson, G. E. (2009). Honey bee aggression supports a link between gene regulation and behavioral evolution. Proceedings of the National Academy of Sciences of the United States of America, 103(36). 15400-15404. doi: 10.1073/pnas.0907043106

Alem, S., Perry, C. J., Zhu, X., Loukola, O. J., Ingraham, T., Søvik, E., Chittka, L. (2016) Associative mechanisms allow for social learning and cultural transmission of string pulling in an insect. PLOS Biology, 14(12): e1002589. doi: 10.1371/journal.pbio.1002589

Anaconda (2019). Anaconda Software Distribution (Version 4.6.14). [Computer software]. Available from http://www.anaconda.com.

Peer) reviewing PDF | (2020:07:50899:2:0:NEW 27 Jan 2021) 
526 Avalos, A., Pérez, E., Vallejo, L., Pérez, M., Abramson, C. I., \& Giray, T. (2017). Social signals

527 and aversive learning in honey bee drones and workers. Biology Open, 6, 41-49. doi:

528 10.1242/bio.021543

529

530

531

532

533

534

535

536

537

538

539

540

541

542

543

544

545

546
Avarguès-Weber, A., \& Giurfa, M. (2013). Conceptual learning by miniature brains. Proceedings of the Royal Society B: Biological Sciences. doi: 280:2013190.

Bildstein, K. L. (1983). Why white-tailed deer flag their tails. The American Naturalist, 121(5), 709-715. doi:10.1086/284096.

Blacquière, T., Cornelissen, B., \& Donder, J. (2007). Bumble bee colony decline in greenhouses with supplemental lighting. Proceedings of the Netherlands Entomological Society Meeting, 18, 71-77.

Brower, L. P., Brower, J. V. Z., \& Westcott, P. W. (1960). Experimental studies of mimicry. 5. The reactions of toads (Bufo terrestris) to bumblebees (Bombus americanorum) and their robber fly mimics (Mallophora bomboides), with a discussion of aggressive mimicry. The American Naturalist, 94(878), 343-355. doi: 10.1086/282137

Carew, T. J., Pinsker, H. M., \& Kandel, E. R. (1972). Long-term habituation of a defensive withdrawal reflex in Aplysia. Science, 175(4020), 451-454. doi: 10.1126/science.175.4020.451

Castellucci, V. F., \& Kandel, E. R. (1974). A Quantal analysis of the synaptic depression underlying habituation of the gill-withdrawal reflex in Aplysia. Proceedings of the National Academy of Sciences of the United States of America, 71(12), 5004-5008. doi: 10.1073/pnas.71.12.5004

Peer) reviewing PDF | (2020:07:50899:2:0:NEW 27 Jan 2021) 
547 Castellucci, V., Pinsker, H., Kupfermann, I., \& Kandel, E. R. (1970). Neuronal mechanisms of

548 habituation and dishabituation of the gill-withdrawal reflex in Aplysia. Science, 167, 549 1747-1748. doi: 10.1126/science.167.3926.1745

550 Charlton, N. L., Houston, A. I. (2010). What currency do bumble bees maximize? PLoS ONE $551 \quad 5(8):$ e12186. https://doi.org/10.1371/journal.pone.0012186

552 Clogg, C. C., Petkova, E., \& Haritou, A. (1995). Statistical methods for comparing regression 553 coefficients between models. American Journal of Sociology, 100(5), 1261-1293. doi:

554 $10.1086 / 230638$

555 Cloudsley-Thompson, J. L. (1995). A review of the anti-predator devices of spiders. Bulletin of 556 the British Arachnological Society, 10(3), 81-96.

557 558

559

560

561

562

563

564 565

566

567

568

569

Craig, D. P. A., Varnon, C. A., Sokolowski, M. B. C., Wells, H., \& Abramson, C. I. (2014). An assessment of fixed interval timing in free-flying honey bees (Apis mellifera ligustica): An analysis of individual performance. PloS One, 9, e101262. doi:10.1371/journal.pone.0101262.

Davis, H., \& Heslop, E. (2004). Habituation of hissing by Madagascar hissing cockroaches (Gromphadorhina portentosa): Evidence of discrimination between humans? Behavioural Processes, 67(3), 539-543. doi: 10.1016/j.beproc.2004.08.003

Desmedt, L. Baracchi, D., Devaud, J. Giurfa, M., d'Ettorre, P. (2017). Aversive learning of odorheat associations in ants. Journal of Experimental Biology, 220, 4661-4668, doi: $10.1242 /$ jeb. 161737

Djegham, Y., Verhaeghe, J.C, \& Rasmont, P. (1994). Copulation of Bombus terrestris L. (Hymenoptera: Apidae) in captivity. Journal of Apicultural Research, 33(1), 15-20, doi: $10.1080 / 00218839.1994 .11100844$ 
570 Dinges, C. W., Varnon, C. A., Cota, L. D., Slykerman, S. C., \& Abramson, C. I. (2017). Studies

571 of learned helplessness in honey bees (Apis mellifera L.). Journal of Experimental 572 Psychology: Animal Learning and Cognition, 43(2), 147-158. doi: 10.1037/xan0000133.

573 Faber, T., Joerges, J., \& Menzel, R. (1999). Associative learning modifies neural representations 574 of odors in the insect brain. Nature Neuroscience, 2(1), 74-78. doi: 10.1038/4576

575 Fisher, R., \& Tuckerman, R. (1986). Mimicry of bumble bees and cuckoo bumble bees by 576 carrion beetles (Coleoptera: Silphidae). Journal of the Kansas Entomological Society,

577 $59(1), 20-25$.

578 FitzGibbon, C. D. \& Fanshawe, J. H. (1988). Stotting in Thomson's gazelles: An honest signal of 579 condition. Behavioral Ecology and Sociobiology, 23, 2, 69-74.

580 Free, J. B. (1958). The defence of bumblebee colonies. Behavior, 12(3) 233-242. doi:

581 $10.1163 / 156853957 X 00128$

582 Gage, S. L., Ahumada, F., Rivera, A., Graham, H., \& DeGrandi-Hoffman, G. (2018). Smoke 583 conditions affect the release of venom droplet accompanying sting extension in honey

584

585 bees (Hymenoptera: Apidae). Journal of Insect Science, 18(4), 1-7. doi:

586

Galizia C. G., Eisenhardt, D. \& Giurfa, M. (2011). Honeybee Neurobiology and Behavior: A 587 Tribute to Randolf Menzel. Springer Netherlands. doi: 10.1007/978-94-007-2099-2

588

589

590

Geyer, M. A., \& Braff, D. L. (1987). Startle habituation and sensorimotor gating in $10.1093 /$ jisesa/iey073

591 schizophrenia and related animal models. Schizophrenia Bulletin, 13(4), 643-668. doi: $10.1093 / \mathrm{schbul} / 13.4 .643$

592

Giurfa, M. (2003). Cognitive neuroethology: Dissecting non-elemental learning in a honeybee brain. Current Opinion in Neurobiology, 13, 726-735. doi: 10.1016/j.conb.2003.10.015 
593 Giurfa, M., Fabre, E., Flaven-Pouchon, J., Groll, H., Oberwallner, B., Vergoz, V., Roussel, E., \& 594 Sandoz, J. (2009). Olfactory conditioning of the sting extension reflex in honeybees:

595 Memory dependence on trial number, interstimulus interval, intertrial interval, and 596 protein synthesis. Learning \& Memory, 16, 761-765. doi: 10.1101/1m.1603009

597 Giurfa, M., Zhang, S., Jenett, A., Menzel, R., Srinivasan, M. V. (2001). The concepts of 598 'sameness' and 'difference' in an insect. Nature, 410(6831), 930-933.

599 https://doi.org/10.1038/35073582

600 Greene, H. W., \& McDiarmid, R. W. (1981). Coral snake mimicry: Does it occur? Science, 601 213(4513), 1207-1212. doi: 10.1126/science.213.4513.1207

602 Groves, P. M., Thompson, R. F. (1970). Habituation: A dual-process theory. Psychological $603 \quad$ Review, 77, 419-450. doi: $10.1037 / \mathrm{h} 0029810$

604 Hammer, M., \& Menzel, R. (1995). Learning and memory in the honeybee. Journal of 605 Neuroscience, 15(3), 1617-1630. doi: 10.1523/JNEUROSCI.15-03-01617.1995

606 Hardin J., Hilbe J.M. (2003). Generalized Estimating Equations. Boca Raton, FL: Chapman \& $607 \quad$ Hall.

608 Hasson, O. (1991). Pursuit-deterrent signals: Communication between prey and predator. Trends 609 in Ecology \& Evolution, 6(10), 325-329. doi: 10.1016/0169-5347(91)90040-5.

610 Hunsinger, E., Root-Gutteridge, H., Cusano, D. A., \& Parks, S. E. (2017). A description of 611 defensive hiss types in the flat horned hissing cockroach (Aeluropoda insignis).

$612 \quad$ Bioacoustics. doi: 10.1080/09524622.2017.1327371

613 Jandt, J. M., \& Dornhaus, A. (2009). Spatial organization and division of labour in the 614 bumblebee Bombus impatiens. Animal Behaviour, 22, $641-651$. 615 doi:10.1016/j.anbehav.20 08.11.019 
616 Jandt, J. M., Huang, E., \& Dornhaus, A. (2009). Weak specialization of workers inside a bumble

617 bee (Bombus impatiens) nest. Behavioral Ecology and Sociobiology, 63(12), 1829-1836.

618 doi: $10.1007 / \mathrm{s} 00265-009-0810-\mathrm{x}$

619 Jaycox, L. H., Foa, E. B., \& Morral, A. R. (1998). Influence of emotional engagement and

620 habituation on exposure therapy for PTSD. Journal of Consulting and Clinical

$621 \quad$ Psychology, 66(1), 185-192. doi: 10.1037/0022-006X.66.1.185

622 Kodaira, Y., Ohtsuki, H., Yokoyama, J, \& Kawata, M. (2009). Size-dependent foraging gene

623 expression and behavioral caste differentiation in Bombus ignitus. BMC Research Notes,

624 2, 184-189.

625 Koethe, S., Bossems, J., Dyer, A. G., \& Luna, K. (2016). Colour is more than hue: Preferences

626 for compiled colour traits in the stingless bees Melipona mondury and M. quadrifasciata.

627 Journal of Comparative Physiology A, 202, 615-627(2016). doi: 10.1007/s00359-016-

$628 \quad 1115-\mathrm{y}$

629 Leal, M., \& Rodríguez-Robles, J. A. (1995). Antipredator responses of Anolis cristatellus

630 (Sauria: Polychrotidae). Copeia, 1995, 155-161.

631 Linader, N., de Ibrra, N. H., \& Laska, M. (2012). Olfactory detectability of L-amino acids in the

632 European honeybee (Apis mellifera). Chemical Senses, 37(7), 631-638. doi:

$633 \quad 10.1093 /$ chemse/bjs044.

634 Maan, M., \& Cummings, M. (2012). Poison frog colors are honest signals of toxicity, 635 particularly for bird predators. The American Naturalist, 179(1), E1-E14. doi:

$636 \quad 10.1086 / 663197$ 
637 Mustard, J. A., Dews, L., Brugato, A., Dey, K., \& Wright, G. A. (2012). Consumption of an 638 acute dose of caffeine reduces acquisition but not memory in the honey bee. Behavioral 639 Brain Research, 232(1), 217-224. doi: 10.1016/j.bbr.2012.04.014

640 Nicolas, C. L., Abramson, C. I., \& Levin, M. (2008). Analysis of behavior in the planarian 641 model. In R. B. Raffa (Ed.) Planaria: A Model for Drug Action and Abuse. Austin, TX: $642 \quad$ Landes Bioscience.

643 Paternoster, R., Brame, R., Mazerolle, P., \& Piquero, A. (1998). Using the correct statistical test 644 for the equality of regression coefficients. Criminology, 36(4), 859 - 866.

645 Perktold, J., Seabold, S., Taylor, J. (2018). StatsModels (Version 0.9.0). [Computer software]. $646 \quad$ Available from http://www.statsmodels.org.

647 Place, A. J. \& Abramson, C. I. (2008). Habituation of the rattle response in western diamondback 648 rattlesnakes, Crotalus atrox. Copeia, 2008(4), 835-843. doi: 10.1643/CE-06-246

649 Plowright, R. C., \& Owen R. E. (1980). The evolutionary significance of bumble bee color 650 patterns: A mimetic interpretation. Evolution, 34(4), 622-637. doi: 10.2307/2408017

Pouvreau, A. (1991). Morphology and histology of tarsal glands in bumble bees of the genera Bombus, Pyrobumbus and Megabombus. Canadian Journal of Zoology, 69(4), 866-872.

653 doi: $10.1139 / \mathrm{z} 91-130$

654

Raine, N. E, \& Chittka, L. (2007). Pollen foraging: learning a complex motor skill by 655 bumblebees (Bombus terrestris). Naturwissenschaften, 94(6), 459-464

Raine, N. E., \& Chittka, L. (2008). The correlation of learning speed and natural foraging

657 success in bumble-bees. Proceedings of the Royal Society B, 275, 803-808.

Rankin, C. H., Abrams, T., Barry, R. J., Bhatnager, S., Claytong, D., Colombo, J., . . . Thompson, R. F. (2009). Habituation revisited: An updated and revised description of the 
660

661

662 663

664 665 666 667 668 669 670 671 672 673 674 675 676

677 678 679 680 681

behavioral characteristics of habituation. Neurobiology of Learning and Memory, 92(2): 135-138. doi: 10.1016/j.nlm.2008.09.012.

Ritson-Williams, R., \& Paul, V. J. (2007). Marine benthic invertebrates use multimodal cues for defense against reef fish. Marine Ecology Progress Series, 340(29), 29-39. doi: $10.3354 /$ meps340029

Riveros, A. J., \& Gronenberg, W. (2009a). Learning from learning and memory in bumblebees. Communicative \& Integrative Biology, 2(5), 437-440. doi: 10.4161/cib.2.5.9240

Riveros, A. J., \& Gronenberg, W. (2009b). Olfactory learning and memory in the bumblebee Bombus occidentalis. Naturwissenschaften, 96: 851-856. doi: 10.1007/s00114-009-0532-

Rossi, N., d'Ettorre, P., Giurfa, M. (2018). Pheromones modulate responsiveness to a noxious stimulus in honey bees. Journal of Experimental Biology, 221, 1-10, doi: $10.1242 /$ jeb. 172270

Rowe, C., \& Guilford, T. (1999). The evolution of multimodal warning displays. Evolutionary Ecology, 13(7-8), 655-671.

Rowe, C., \& Haplin, C. (2013). Why are warning displays multimodal. Behavioral Ecology and Sociobiology, 67(9), 1425-1439.

Schmitt, U. (1990). Hydrocarbons in tarsal glands of Bombus terrestris. Experientia, 45(10) 1080-1082.

Schulz, D. J., Haung, Z., \& Robinson, G. E. (1998). Effects of colony food shortage on behavioral development in honey bees, 45(5), 295-303. 
682 Scienza, L., Pinheiro de Carvalho, M., Machado, A., Moreno, A. M., Biscassi, N., \& Graças de

683

684

685

686

687

688

689

690

691

692

693

694

695

696

697

698

699

700

701

702

703

704

Souza, D. (2019). Simple discrimination in stingless bees (Melipona quadrifasciata):

Probing for select- and reject-stimulus control. Journal of the Experimental Analysis of Behavior, 112, 1-14. doi: 10.1002/jeab.531

Sheppard, W. S., Arias, M. C., Grech, A., \& Meixner, M. D. (1997). Apis mellifera ruttneri, a new honey bee subspecies from Malta. Apidologie, 28(5), 287-293. doi: 10.1051/apido:19970505

Shotton, R. (2014). Testing the disturbance hiss of the Madagascar hissing cockroach (Gromphadorhina portentosa) as an anti-predatory response. Bioscience Horizons: The International Journal of Student Research, 7, 1-7. doi: 10.1093/biohorizons/hzu010

Skorupski, P., \& Chittka, L. (2010). Photoreceptor spectral sensitivity in the bumblebee, Bombus impatiens (Hymenoptera: Apidae). PLoS ONE, 5(8): e12049. doi: 10.1371/journal.pone.0012049

Spaethe, J., \& Weidenmüller, A., (2002). Size variation and foraging rate in bumblebees (Bombus terrestris). Insectes Sociaux, 49(2), 142-146.

Spivak, M., (1997). Honey bee hygienic behavior and defense against Varroa jacobsoni. Apidologie, 27, 245-260, doi: 10.1051/apido:19960407

Stanley, D. A., Smith, K. E., \& Raine, N. E., (2015). Bumblebee learning and memory is impaired by chronic exposure to a neonicotinoid pesticide. Scientific Reports, 5(16508), 1-10. doi: 1038/srep16508

Strang, C. G., \& Sherry, D. F. (2014). Serial reversal learning in bumblebees (Bombus impatiens). Animal Cognition, 17, 723-734. doi: 10.1007/s10071-013-0704-1 
705 Tautz, J., Maier, S., Groh, C., Rössler, W., \& Brockman A., (2003). Behavioral performance in

706 adult honey bees is influenced by the temperature experienced during their pupal

707 development. Proceedings of the National Academy of Sciences of the United States of

708 America, 10(12), 7343-7347. doi: 10.1073/pnas.1232346100

709 Tedjakumala, S. R., Guirfa, M. (2013). Rules and mechanisms of punishment learning in honey

710 bees: the aversive conditioning of the sting extension response. Journal of Experimental

711 Biology, 216: 2985-2997; doi: 10.1242/jeb.086629

712 Thompson, R. F., \& Spencer, W. A. (1966). Habituation: A model phenomenon for the study of 713 neuronal substrates of behavior. Psychological Review, 73(1), 16-43. doi:

$714 \quad 10.1037 / \mathrm{h} 0022681$

715 Varnon, C. A., Dinges, C. W., Black, T. E., Wells, H., \& Abramson, C. I. (2018). Failure to find 716 ethanol-induced conditioned taste aversion in honey bees (Apis mellifera L.). Alcoholism:

717 Clinical and Experimental Research, 42(7), 1260-1270. doi: 0.1111/acer.13761.

718 Varnon, C. A., Lang, H., \& Abramson, C. I. (2018). Automated research in comparative

719 psychology: Limitations and new directions. International Journal of Comparative

$720 \quad$ Psychology, 31, 1-17.

721 Vergoz, V., Roussel, E., Sandoz, J., \& Giurfa, M. (2007). Aversive learning in honeybees

722 revealed by the olfactory conditioning of the sting extension reflex. PLoS ONE 2(3):

723 e288. doi: 10.1371/journal.pone.0000288 
Figure 1

The disturbance leg-lift response (DLR) of the bumble bee. Artwork by Jennifer Salazar. Original reference photographs by Ivan Mikhaylov.
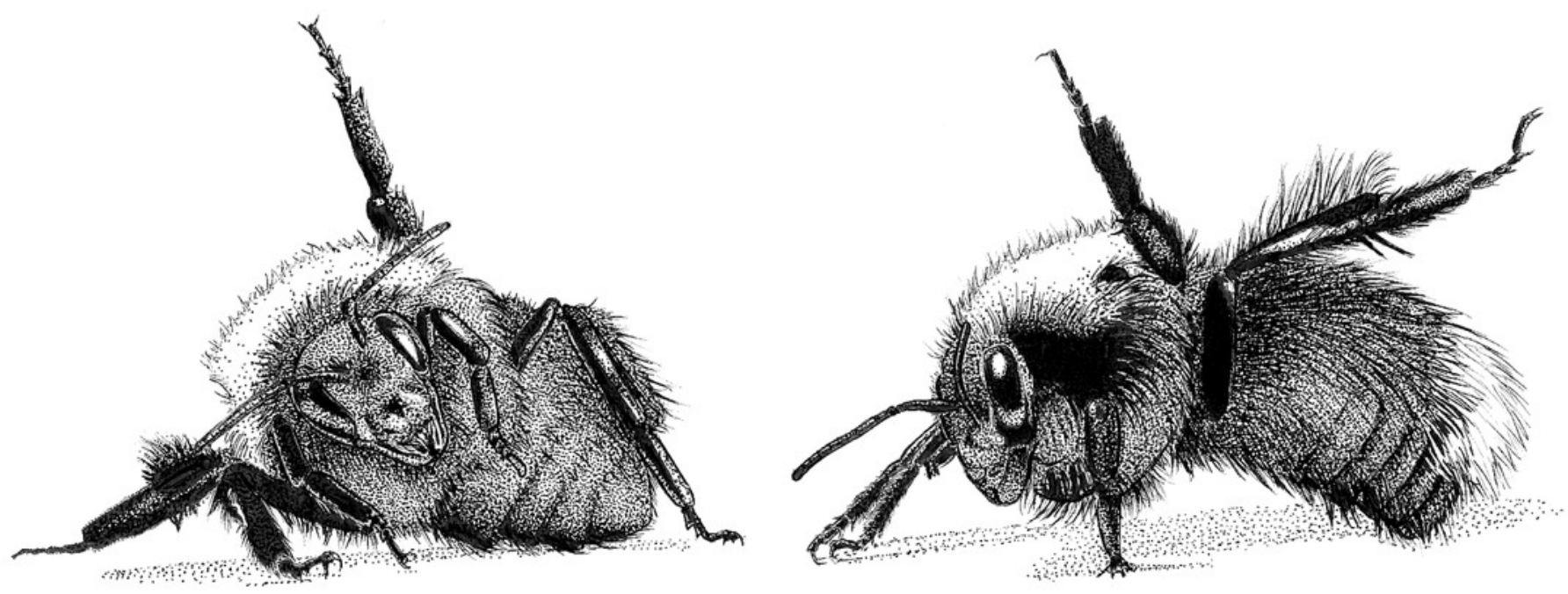
Figure 2

Percent of trials where bees emitted DLR, bite or sting for the experimental group (A) and control group (B). Error bars show standard error of the mean.
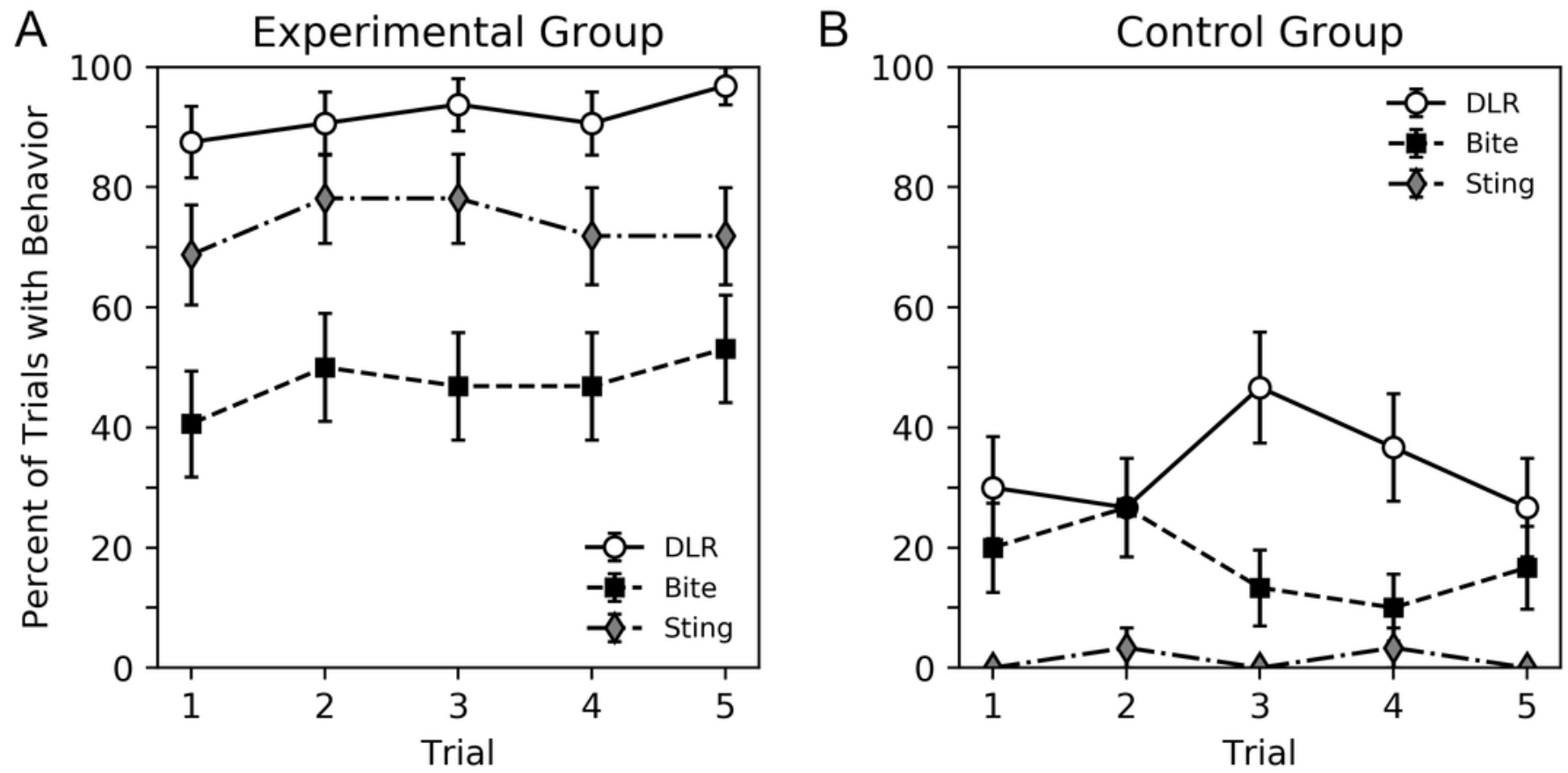
Figure 3

Average number of legs lifted during trials where DLR occurred for the experimental and control groups. Error bars show standard error of the mean.

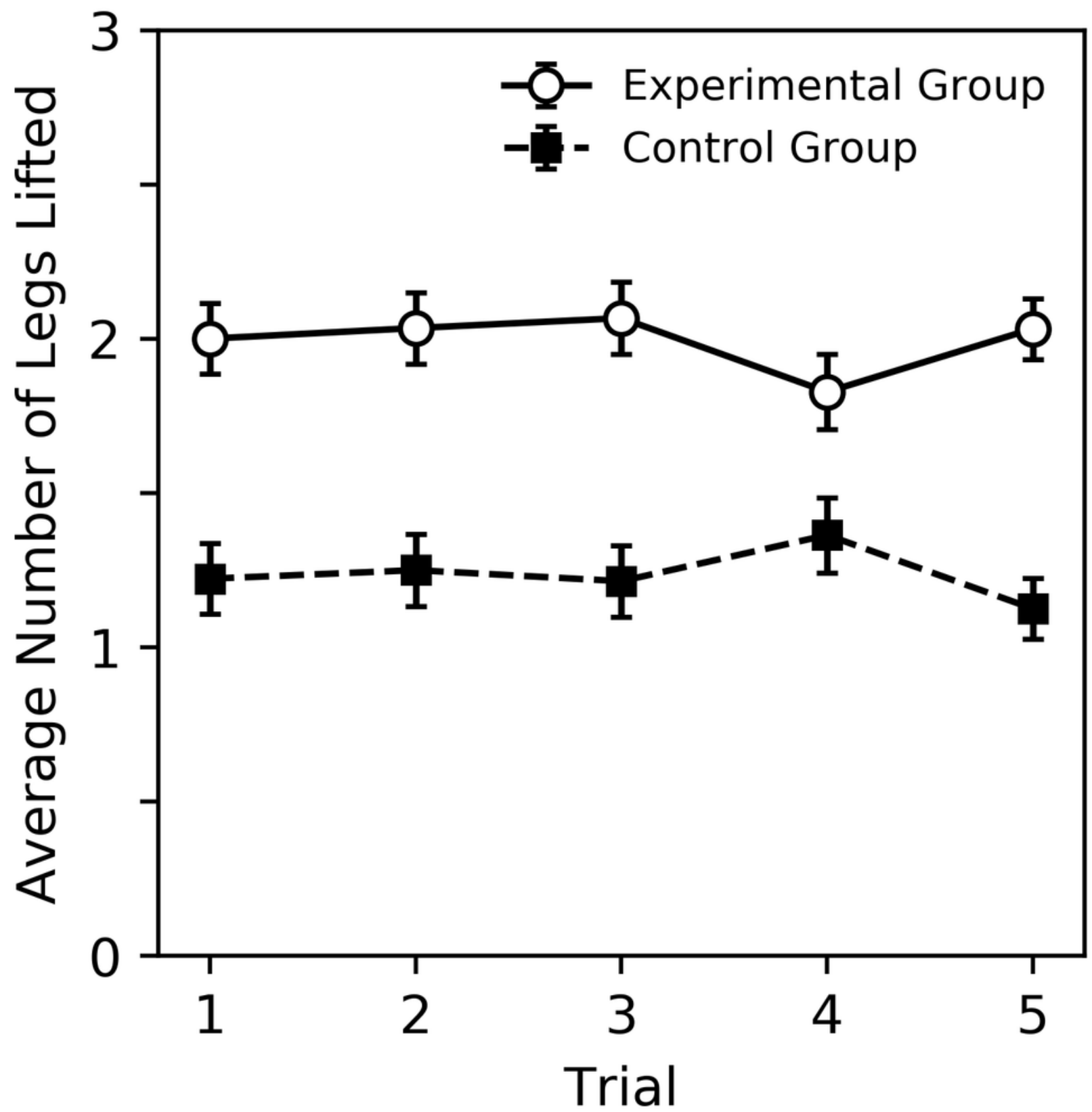


Figure 4

Percent of captive and wild bees emitting DLR across the 10 habituation trials and final three control trials. Sixty-four subjects per sample were used in trials 1 to 10 . The final three trials represent 32 subjects per sample. Error bars show standard er

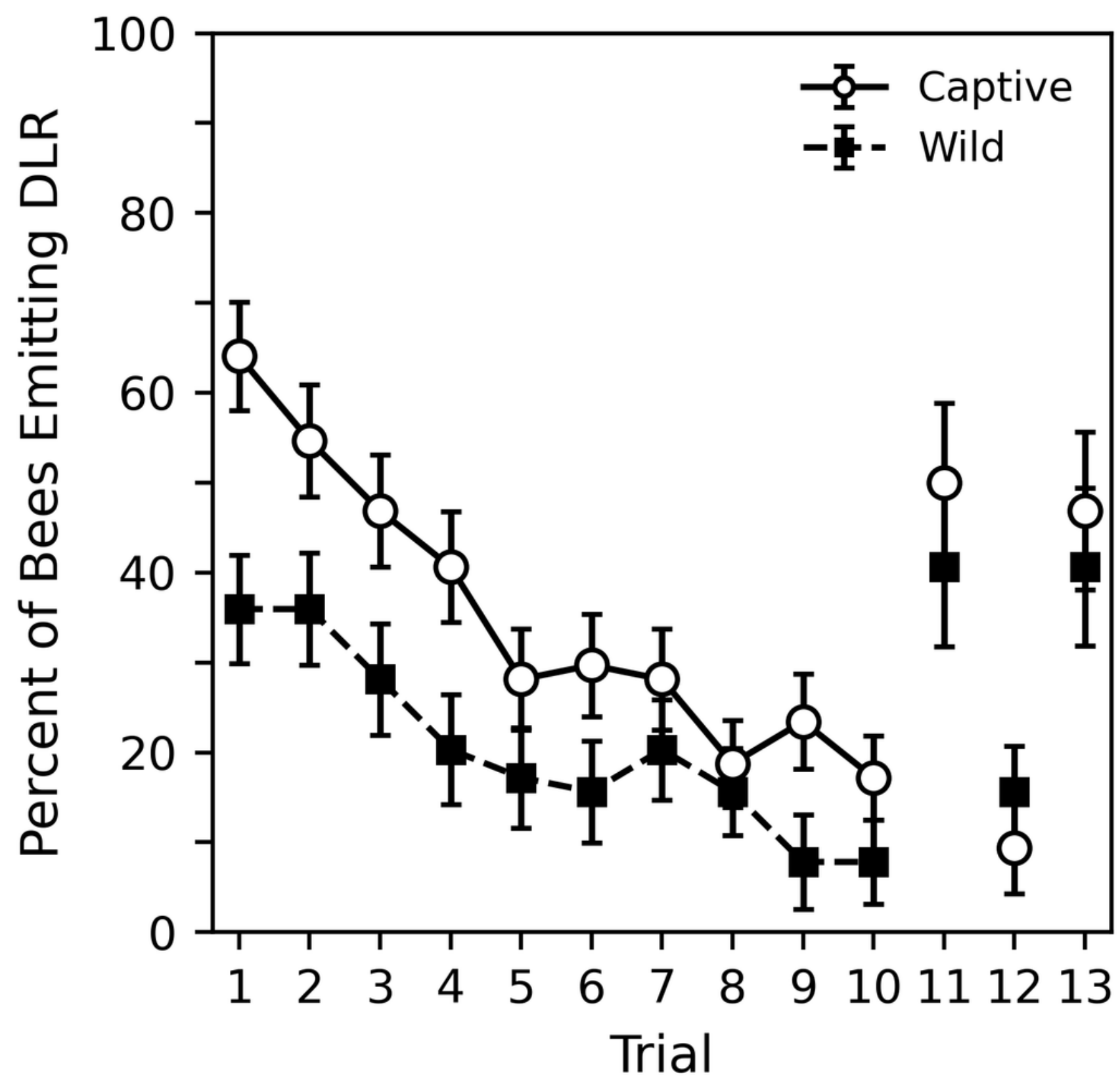


Table $\mathbf{1}$ (on next page)

Percent of Trials with Behavior Sequence 
1 Table 1

Percent of Trials with Behavior Sequence

\begin{tabular}{lcc}
\hline Behavior Sequence & Experimental & Control \\
\hline Inactive & 3.12 & 51.33 \\
\hline DLR & 18.12 & 30.67 \\
DLR:Bite & 1.25 & 0.00 \\
DLR:Sting & 30.00 & 0.67 \\
DLR:Bite:Sting & 16.25 & 0.00 \\
DLR:Sting:Bite & 15.62 & 0.00 \\
\hline Bite & 2.50 & 14.67 \\
Bite:DLR & 1.25 & 2.00 \\
Bite:Sting & 1.25 & 0.67 \\
Bite:DLR:Sting & 5.62 & 0.00 \\
Bite:Sting:DLR & 2.50 & 0.00 \\
\hline Sting & 0.62 & 0.00 \\
Sting:DLR & 0.62 & 0.00 \\
Sting:Bite & 0.62 & 0.00 \\
Sting:DLR:Bite & 0.00 & 0.00 \\
Sting:Bite:DLR & 0.62 & 0.00 \\
\hline
\end{tabular}

2 
Table 2 (on next page)

Experimental Group Sequence Regression 
1 Table 2

Experimental Group Sequence Regression

\begin{tabular}{lccccc}
\hline Sequence & Estimate & Standard Error & \multicolumn{2}{c}{$95 \%$ Confidence Intervals } & $p$ value \\
\hline Inactive & -0.726 & 0.424 & -1.557 & 0.105 & 0.087 \\
\hline DLR & 1.200 & 0.306 & 0.601 & 1.799 & 0.000 \\
DLR:Bite & -1.661 & 0.693 & -3.020 & -0.303 & 0.017 \\
DLR:Sting & 1.861 & 0.183 & 1.501 & 2.220 & 0.000 \\
DLR:Bite:Sting & 1.068 & 0.229 & 0.619 & 1.517 & 0.000 \\
DLR:Sting:Bite & 1.022 & 0.266 & 0.500 & 1.543 & 0.000 \\
\hline Bite & -0.956 & 0.601 & -2.134 & 0.223 & 0.112 \\
Bite:DLR & -1.661 & 0.693 & -3.020 & -0.303 & 0.017 \\
Bite:Sting & -1.661 & 0.693 & -3.020 & -0.303 & 0.017 \\
Bite:DLR:Sting & -0.112 & 0.343 & -0.784 & 0.560 & 0.744 \\
Bite:Sting:DLR & -0.956 & 0.601 & -2.134 & 0.223 & 0.112 \\
\hline Sting & -2.361 & 0.990 & -4.302 & -0.420 & 0.017 \\
Sting:DLR & -2.361 & 0.990 & -4.302 & -0.420 & 0.017 \\
Sting:Bite & -2.361 & 0.990 & -4.302 & -0.420 & 0.017 \\
Sting:DLR:Bite & -16.495 & 0.177 & -16.841 & -16.148 & 0.000 \\
Sting:Bite:DLR & -2.361 & 0.990 & -4.302 & -0.420 & 0.017 \\
\hline
\end{tabular}

2 
Table 3 (on next page)

Control Group Sequence Regression 
$1 \quad$ Table 3

Control Group Sequence Regression

\begin{tabular}{lccccc}
\hline Sequence & Estimate & Standard Error & \multicolumn{2}{c}{$95 \%$ Confidence Intervals } & $p$ value \\
\hline Inactive & 2.761 & 0.247 & 2.278 & 3.245 & 0.000 \\
\hline DLR & 1.892 & 0.269 & 1.366 & 2.419 & 0.000 \\
DLR:Bite & -17.495 & 0.183 & -17.853 & -17.137 & 0.000 \\
DLR:Sting & -2.296 & 0.990 & -4.236 & -0.356 & 0.020 \\
DLR:Bite:Sting & -17.495 & 0.183 & -17.853 & -17.137 & 0.000 \\
DLR:Sting:Bite & -17.495 & 0.183 & -17.853 & -17.137 & 0.000 \\
\hline Bite & 0.947 & 0.291 & 0.377 & 1.518 & 0.001 \\
Bite:DLR & -1.184 & 0.559 & -2.279 & -0.088 & 0.034 \\
Bite:Sting & -2.296 & 0.990 & -4.236 & -0.356 & 0.020 \\
Bite:DLR:Sting & -17.495 & 0.183 & -17.853 & -17.137 & 0.000 \\
Bite:Sting:DLR & -17.495 & 0.183 & -17.853 & -17.137 & 0.000 \\
\hline Sting & -17.495 & 0.183 & -17.853 & -17.137 & 0.000 \\
Sting:DLR & -17.495 & 0.183 & -17.853 & -17.137 & 0.000 \\
Sting:Bite & -17.495 & 0.183 & -17.853 & -17.137 & 0.000 \\
Sting:DLR:Bite & -16.495 & 0.183 & -16.853 & -16.137 & 0.000 \\
Sting:Bite:DLR & -17.495 & 0.183 & -17.853 & -17.137 & 0.000 \\
\hline
\end{tabular}


Table 4 (on next page)

Experimental Group DLR-first Pairwise Comparisons 
1 Table 4

Experimental Group DLR-first Pairwise Comparisons

\begin{tabular}{lccc}
\hline Comparison & Estimate Difference & z score & $p$ value \\
\hline DLR:Bite vs. DLR & -2.862 & -3.776 & 0.000 \\
DLR:Bite vs. DLR:Sting & -3.522 & -4.911 & 0.000 \\
DLR:Bite vs. DLR:Bite:Sting & -2.730 & -3.738 & 0.000 \\
DLR:Bite vs. DLR:Sting:Bite & -2.683 & -3.613 & 0.000 \\
DLR:Sting vs. DLR & 0.661 & 1.852 & 0.064 \\
DLR:Sting vs. DLR:Bite:Sting & 0.792 & 2.700 & 0.007 \\
DLR:Sting vs. DLR:Sting:Bite & 0.839 & 2.597 & 0.009 \\
\hline
\end{tabular}

2 
Table 5 (on next page)

Change in DLR Across Trial 
1 Table 5

Change in DLR Across Trial

\begin{tabular}{|c|c|c|c|c|c|}
\hline Parameter & Estimate & Standard Error & \multicolumn{2}{|c|}{$95 \%$ Confidence Intervals } & $p$ value \\
\hline Captive & 0.587 & 0.210 & 0.177 & 0.998 & 0.005 \\
\hline Wild & -0.344 & 0.243 & -0.821 & 0.132 & 0.157 \\
\hline Captive $*$ Trial & -0.232 & 0.035 & -0.301 & -0.163 & 0.000 \\
\hline Wild $*$ Trial & -0.202 & 0.042 & -0.284 & -0.120 & 0.000 \\
\hline
\end{tabular}

2 
Table 6(on next page)

Pairwise Comparisons of Trials 
1 Table 6

2

Pairwise Comparisons of Trials

\begin{tabular}{|c|c|c|c|}
\hline Comparison & Difference & z score & $p$ value \\
\hline Captive 1 : Captive 10 & 2.325 & 3.609 & 0.000 \\
\hline Captive 1 : Captive 11 & 0.379 & 0.752 & 0.452 \\
\hline Captive 1 : Captive 12 & 2.648 & 3.755 & 0.000 \\
\hline Captive 1 : Captive 13 & 0.505 & 0.999 & 0.318 \\
\hline Captive 10 : Captive 11 & -1.946 & -3.036 & 0.002 \\
\hline Captive 10 : Captive 12 & 0.323 & 0.399 & 0.690 \\
\hline Captive 10 : Captive 13 & -1.821 & -2.839 & 0.005 \\
\hline Captive 11 : Captive 12 & 2.269 & 3.232 & 0.001 \\
\hline Captive 11 : Captive 13 & 0.125 & 0.250 & 0.803 \\
\hline Captive 12 : Captive 13 & -2.144 & -3.052 & 0.002 \\
\hline Wild 1 : Wild 10 & 2.325 & 3.609 & 0.000 \\
\hline Wild 1 : Wild 11 & 0.379 & 0.752 & 0.452 \\
\hline Wild 1 : Wild 12 & 2.648 & 3.755 & 0.000 \\
\hline Wild 1 : Wild 13 & 0.505 & 0.999 & 0.318 \\
\hline Wild 10 : Wild 11 & -1.946 & -3.036 & 0.002 \\
\hline Wild 10 : Wild 12 & 0.323 & 0.399 & 0.690 \\
\hline Wild 10 : Wild 13 & -1.821 & -2.839 & 0.005 \\
\hline Wild 11 : Wild 12 & 2.269 & 3.232 & 0.001 \\
\hline Wild 11 : Wild 13 & 0.125 & 0.250 & 0.803 \\
\hline Wild 12 : Wild 13 & -2.144 & -3.052 & 0.002 \\
\hline
\end{tabular}

3 